\title{
Okul Öncesi Öğretmenlerinin Yaratıcı Düşünme Eğilimleri
}

\author{
DOI: 10.26466/opus.580091 \\ * \\ Seda Eskidemir Meral ${ }^{*}$ - Fatma Tezel Şahin** \\ * Öğr.Gör., Akdeniz Üniversitesi, Sağlık Hizmetleri MYO, Antalya / Türkiye \\ E-Posta: seskidemir@gmail.com \\ ORCID: $\underline{0000-0002-3129-4908}$ \\ ** Prof. Dr., Gazi Üniversitesi, Gazi Eğitim Fakültesi, Ankara/ Türkiye \\ E-Posta: ftezel68@gmail.com \\ ORCID: $\underline{0000-0003-2098-2411}$
}

\section{Öz}

Yaratıcllı, kavramlar arasinda herkesten farklı ilişkiler kurarak yeni, orijinal ve faydalı bir fikir ya da ürün üretebilme, kalıpların dışına çıkabilme, probleme farklı açılardan bakabilme becerisidir. Yaratıcı düşünme ise, daha önce aralarında ilişki kurulmamış nesneler ya da düşünceler arasında ilişki kurulmasıdır. Yaratıcılık herkesin doğuştan getirdiği bir yetenektir ve daha da yaratıcı olmak öğretilebilir. Yaratıcı öğretmenlerin sınıfındaki çocuklar yaratıcı olurlar. İnsan kendisi yaratıcı değilse yaratıcılı̆̆ öğretmesi, desteklemesi de güçtür. Okul öncesi öğretmenlerinin yaratıcı düşünme becerilerine sahip olmasının sımıflarındaki çocukların da yaratıcılıklarm etkileyeceği ve okul öncesi eğitimin niteliğini arttıracă̆̆ düşünülmektedir. Bu noktadan hareketle çalışmanın amacı okul öncesi öğretmenlerinin yaratıcı dü̈sünme eğilimlerinin çeşitli değiş̧kenler açısından incelenmesidir. Araştırmada tarama modeli kullanılmıştır. Araştırmanın çalışma grubunu okul öncesi eğitim kurumunda görev yapan 160 okul öncesi öğretmeni oluşturmaktadır. Araştırmanın verileri; öğretmenlerin kişisel bilgilerini belirlemek amactyla hazırlanan "Genel Bilgi Formu", Özgenel ve Çetin (2017) tarafindan geliştirilen "Marmara Yaratıcı Düşünme Eğilimleri Ölçeği" ile toplanmıştır. Araştırmanın sonucunda, öğretmenlerin yaratıc düşünme eğilimlerinin yüksek olduğu; yaratıcı düşünme eğilimleri ile yaş, mezun olunan bölüm, medeni durum, çocuk sahibi olma durumu, mesleki kıdem, sinifinda bulunan çocuk sayısı, sınıfindaki çocukların yaşı, hizmet içi eğitimlere katılma durumu arasında anlamlı bir fark olmadığı görülmüş̧ür

Anahtar Kelimeler: Okul Öncesi Öğretmeni, Yaratıcı Düşünme, Yaratıcılı 


\title{
Creative Thinking Dispositions of The Preschool Teachers
}

\begin{abstract}
Creativity is the skill of being able to produce a new, original and beneficial idea or a product, getting out of cliche, being able to have a different point of view for a problem by making more different relations than others between concepts. Creative thinking is making a relation between the objects and thoughts which did not have a relation before. Creativity is an innate ability, and being more creative could be taught. Children in the classes of creative teachers are creative. If one is not creative, it is difficult to teach and support creativity. It is thought that preschool teachers' having creative thinking skills will affect the creativity of children in classrooms and increase the quality of preschool education.In this sense, the purpose of the current study is to investigate the creative thinking dispositions of preschool teaches in terms of different variables. Survey model was used in the study. The working group of the study was made up of 160 preschool teaches working at a preschool education institution.The data of the study was collected through "General Information Form" that was prepared to determine the personal information of the teacher and "Marmara Scale of Creative Thinking Dispositions" that was developed by Özgenel and Çetin (2017). At the end of the research, it was found that creative thinking dispositions of the teachers were high; there was no significant difference between the creative thinking dispositions and the age, the department graduated, marital status, the status of having a child, occupational experience, the number of children in the classroom, the ages of the children in the class, and the status of participating in an in-service training course.
\end{abstract}

Keywords Preschool teacher, creative thinking, creativity 


\section{Giriş}

Yaratıcılık, kavramlar arasında herkesten farklı ilişkiler kurarak yeni, orijinal ve faydalı bir fikir ya da ürün üretebilme, kalıpların dışına çıkabilme, probleme farklı açlardan bakabilme becerisidir(Ayden ve İşguzar, 2006). Torrance (1965) yaratıcllı̆ın; problemlere, uyumsuzluğa karşı duyarlı olma; problemleri tanımlama, zorlukları tanıma, çözümler arama, probleme farklı çözüm yolları bulma ve bunları deneme olduğunu ifade etmiştir. Yaratıcı düşünme ise, daha önce aralarında ilişki kurulmamış nesneler ya da düşünceler arasında ilişki kurulmasıdır (Rawlinson,1995). Yaratıcılık herkesin doğuştan getirdiği bir yetenektir ve daha da yaratıcı olmak öğretilebilir (Üstündağ, 2014). Yaratıcılığ1 geliştirmeye yönelik hazırlanan eğitim programlarının yaratıcılığı geliştirdiği yapılan çalışmalarla ortaya konulmuştur (Dere ve Ömeroğlu, 2018; Yıld1z, 2000).

Çocukların yaratıcılıklarının desteklenmesi için öğretmenlerin de yaratıcllıklarının geliştirilmesi önemlidir (Argun, 2012). Yaratıcı öğretmenlerin sınıfındaki çocuklar yaratıcı olurlar. İnsan kendisi yaratıcı değilse yaratıcılığı öğretmesi, desteklemesi de güçtür (Üstündağ, 2014). Bu nedenle çocukların yaratıcı düşünme becerilerinin geliştirilebilmesi için okul öncesi öğretmenlerinin yaratıcı düşünme becerilerine sahip olmaları ve çocuklarda bu beceriyi nasıl geliştireceklerini bilmelerinin önemli olduğu düşünülmektedir. Torrance (1969) çocukların yaratıcılıklarının dört yaşlarında en üst düzeye ulaştı̆̆ını, bu nedenle okul öncesi dönemin yaratıcılığın altın yılları olarak görülmesi gerektiğini ifade etmiştir (Akt: Sönmez Ektem, 2017). Okul öncesi öğretmeninin kendisinin yarat1C1 olması, çocukların yaratıcılığının geliştirilmesine inanması ve buna uygun düzenlemeler yapması yaratıcı bir atmosferin oluşmasını sağlar (Çetingöz, 2002). Okul öncesi öğretmenlerinin yaratıcı olmasının çocukların farklı özelliklerine ve yeteneklerine, kendilerini farklı ifade ediş biçimlerine, farklı fikirlerine açık olması, çocukların bağımsız olmalarına fırsat vermesi, onların özgürce hareket edebilecekleri yaratıcılığı destekleyen özgür bir çevre oluşturması açısından da önemli olduğu söylenebilir. Yaratıcı öğretmenler, çocukların hayal kurmasına, probleme farklı çözüm yolları bulmasına, yeni fikirler ortaya koymasına, farklı materyallerle etkileşim kurarak kendi yeteneklerinin ve güçlerinin farkına varma- 
sina destek olurlar (Argun, 2012). Yaratıcı öğretmenler yanlış yaptıklarında bunun üstesinden gelme yolları ararlar, yaratıcı olmayan öğretmenler ise yanlış yaptıklarının farkında bile olmazlar (Bartel, 2000'den aktaran Üstündağ, 2014).

İlgili alan yazına bakıldığında okul öncesi öğretmenlerinin yaratıcılıklarının yüksek olduğunu (Çoban, 2016) okul öncesi öğretmenlerinin yaratıcılığın önemine inandıklarını ortaya koyan(Alkuş ve Olgan 2014; Cheung ve Leung, 2013,Yıldırım, 2006) çalışmaların olduğu görülmektedir. Bununla beraber okul öncesi öğretmenlerinin uyguladıkları etkinliklerin yaratıcılığı desteklemesi bakımından yetersiz olduğunu ortaya koyan (Sönmez Ektem, 2017) ve okul öncesi öğretmenlerinin yaratıcıllğ 1 geliştirmek için desteğe ihtiyaçları olduklarını ifade ettikleri çalışmalar (Cheung ve Leung, 2013) da bulunmaktadır.

Öğretmenlerin yaratıcllıklarının çocukların yaratıcıllı̆̆ 1 ve eğitimin niteliği ile ilişkisini ortaya koyan çalışmalar da mevcuttur. Broinowski (2002), tarafından yapılan araştırmada öğretmenin sahip olduğu sezgi ve hayal gücü ile çocukların yaratıcılığı ve hayal gücü arasında olumlu bir ilişki olduğu bulunmuştur. Eğitimcinin yaratıcılık yeteneğinin çocukların eğitiminde ve onların eğitim hayatını zenginleştirmede en önemli faktör olduğu ifade edilmiştir. Erdoğdu (2006) tarafından yapılan çalışmada da öğretmenlerin çocuklara olan yaklaşımının onların yaratıcılıklarını etkilediği bulunmuştur. Ölçer ve Aşıkoğlu Özdemir (2018) yaptığ1 çalışmada okul öncesi öğretmenlerinin yaratıcı olmasının çocukların fen öğrenimini anlamlı derecede yordadığını ortaya koyarken Zembat, İlçi Küsmüş ve Yılmaz (2018) okul öncesi öğretmenlerinin yaratıcı düşünme eğilim düzeyleri arttıkça, sınıf yönetimi beceri düzeylerinin de arttı̆̆ını ortaya koymuştur. Zeytun (2010) tarafından yapılan çalışmada okul öncesi öğretmenliği öğrencilerinin yaratıcılıkları ile problem çözme becerileri arasında pozitif yönde anlamlı bir ilişki olduğu bulunmuştur.

Okul öncesi öğretmenlerinin yaratıcı düşünme becerilerine sahip olmasının sınıflarındaki çocukların da yaratıcılıklarını etkileyeceği ve okul öncesi eğitimin niteliğini arttıracağ düş̧ünülmektedir. Bu noktadan hareketle bu çalışmanın amacı okul öncesi öğretmenlerinin yaratıcı düşünme eğilimlerinin çeşitli değişkenler açısından incelenmesidir. Bu temel amaç doğrultusunda aşağıdaki sorulara cevap aranmıştır: 
- Okul öncesi öğretmenlerinin yaratıcı düşünme eğilimleri ne düzeydedir?

- Okul öncesi öğretmenlerinin yaratıcı düşünme eğilimleri sosyodemografik özelliklerine göre (mezun olunan bölüm, yaş, mesleki kıdem, çalıştığ1 yaş grubu, sınıf mevcudu, hizmet içi eğitimlere katılma durumu) anlamlı bir farklılık göstermekte midir?

\section{Yöntem}

\section{Araştırmanın Modeli}

Araştırmada tarama modeli kullanılmıştır. Tarama modeli, geçmişte veya devam etmekte olan bir durumu, var olduğu şekliyle betimlemeyi amaçlamaktadır (Karasar, 2005). Bu çalışmada da okul öncesi öğretmenlerinin yaratıcı düşünme eğilimleri betimlenmeye çalışılmıştır.

\section{Çalışma Grubu}

Tablo 1. Çalışma Grubundaki Öğretmenlerin Demografik Bilgileri

\begin{tabular}{llll}
\hline & & $\mathrm{f}$ & $\%$ \\
\hline \multirow{2}{*}{ Mezun Olunan Bölüm } & Okul Öncesi Öğretmenliği & 127 & 79,4 \\
& Diğer(Çocuk Gelişimi Anaokulu Öğretmenliği) & 33 & 20,6 \\
\hline Yaş & 30 ve altı & 38 & 23,8 \\
& $31-35$ & 58 & 36,3 \\
& 36 ve üstü & 64 & 40 \\
\hline Mesleki Kıdem & $0-5$ yıl & 26 & 16,3 \\
& $6-10$ yll & 60 & 37,5 \\
& $11-15$ yıl & 44 & 27,5 \\
& 16 ve üstü & 30 & 18,8 \\
\hline Çalıştığı Yaş Grubu & $36-48$ ay & 27 & 16,9 \\
& $49-60$ ay & 84 & 52,5 \\
& 61 ay ve üstü & 49 & 30,6 \\
\hline Sinıf Mevcudu & $1-20$ & 72 & 45,0 \\
& 21 ve üstü & 88 & 55,0 \\
\hline Hizmet içi Eğitime Katılma & Katılma & 132 & 82,5 \\
Durumu & Katılmama & 28 & 17,5 \\
\hline TOPLAM & & 160 & 100,0 \\
\hline
\end{tabular}

Araştırmanın çalışma grubunu Antalya ili Kepez, Muratpaşa, Konyaaaltı, Döşemealtı ve Aksu ilçelerinde okul öncesi eğitim kurumunda görev 
yapan 160 okul öncesi öğretmeni oluşturmaktadır. Çalışma grubundaki öğretmenlerin demografik bilgileri Tablo 1.'de verilmiştir.

\section{Veri Toplama Araçları ve Verilerin Toplanması}

Araştırmanın verileri; öğretmenlerin kişisel bilgilerini belirlemek amacıyla hazırlanan "Genel Bilgi Formu", Özgenel ve Çetin (2017) tarafından geliştirilen "Marmara Yaratıcı Düşünme Eğilimleri Ölçeği" ile toplanmıştır. Marmara Yaratıcı Düşünme Eğilimleri Ölçeği 25 maddeden oluşan 5'li likert tipi bir ölçektir. "Yenilik arama", "cesaret", "öz disiplin", "merak", "şüphe etme" ve "esneklik" olmak üzere 6 boyuttan oluşan ölçek, bireylerin yaratıcı düşünme eğilimlerini ölçmektedir. Ölçeğin tümü için Cronbach alfa iç tutarlılık katsayısı .87 olarak hesaplanmıştır. Ölçekten en az 25 puan, en fazla 125 puan alınmaktadır. Bireyin ölçekten aldığı puanın yüksekliği, yaratıcı düşünme eğiliminin yüksek olduğunu göstermektedir.

Araştırmanın verileri, 2018-2019 eğitim öğretim dönemi bahar yarıyılında ilgili kurumlardan izin alındıktan sonra gönüllü öğretmenlerden yazılı olarak toplanılmıştır.

\section{Verilerin Analizi}

Verilerin analizinde SPSS 23.0 paket programı kullanılmıştır. Yüzde ve frekans gibi istatistikler tablolar halinde verilmiştir. Ölçeklerden alınan puanlar için çarpıklık ve basıklık değerleri $-1,5+1,5$ aralığında değerlendirilmiştir. Tüm verilerin bu aralıkta yer almasından dolayı normal dağılım gösterdiği kabul edilmiştir. Mezun olunan program, sınıf mevcudu, hizmet içi eğitime katılma durumu değişkenine bağlı olarak farklılıkları tespit edebilmek için Bağımsız Örneklemler T Testi kullanılmıştır. Öğretmenlerin yaşı, mesleki kıdemi, çalıştığ1 yaş grubu değişkenine bağlı olarak farklılıkları tespit edebilmek için Varyans analizi kullanılmıştır. 


\section{Bulgular}

Araştırmanın bu bölümünde incelenen değişkenler ile ilgili olarak toplanan verilerin istatistiksel analizi yapılarak bu analizler sonucunda elde edilen bulgular yer almaktadır.

Tablo 2. Öğretmenlerin Marmara Yaratıcı Düşünme Eğilimleri Ölçeğinden Aldıkları Puanlara İlişkin Betimsel İstatistik Değerleri

\begin{tabular}{llll}
\hline & $\mathbf{N}$ & \multicolumn{1}{c}{$\overline{\mathbf{X}}$} & ss \\
\hline Toplam puan & 160 & 102,3688 & 11,09174 \\
\hline Öz disiplin & 160 & 20,0188 & 2,74371 \\
\hline Yenilik Arama & 160 & 32,9250 & 3,97880 \\
\hline Cesaret & 160 & 15,6437 & 2,36150 \\
\hline Merak & 160 & 12,6812 & 1,65735 \\
\hline Şüphe Etme & 160 & 8,4250 & 1,11338 \\
\hline Esneklik & 160 & 12,6750 & 1,50283 \\
\hline
\end{tabular}

Tablo 2.'ye göre öğretmenlerin Marmara yaratıcı düşünme eğilimleri ölçeğinden aldıkları toplam puanlarının yüksek olduğu belirlenmiştir.

Tablo 3. Öğretmenlerin Mezun Oldukları Bölüme Göre Marmara Yaratıcı Düşünme Ĕ̆ilimleri Ölçeğinden Aldıkları Puanlara İlişkin Bağımsız Örneklemler t testi Analizi Sonuçlan

\begin{tabular}{|c|c|c|c|c|c|c|c|}
\hline & $\begin{array}{l}\text { Mezun olunan } \\
\text { bölüm }\end{array}$ & $\mathbf{N}$ & & SS & $\mathbf{t}$ & sd & $\mathbf{p}$ \\
\hline $\begin{array}{l}\text { Toplam } \\
\text { Puan }\end{array}$ & $\begin{array}{l}\text { Okul Öncesi } \\
\text { Öğret. } \\
\text { Diğger }\end{array}$ & $\begin{array}{l}127 \\
33\end{array}$ & $\begin{array}{l}102,5512 \\
101,6667\end{array}$ & $\begin{array}{l}11,76402 \\
8,10735\end{array}$ & ,407 & 158 & 685 \\
\hline Öz disiplin & $\begin{array}{l}\text { Okul Öncesi Öğret. } \\
\text { Diğer }\end{array}$ & $\begin{array}{l}127 \\
33 \\
\end{array}$ & $\begin{array}{l}20,0157 \\
20,0303\end{array}$ & $\begin{array}{l}2,90316 \\
2,05373\end{array}$ &,- 027 & 158 & ,978 \\
\hline Yenilik Arama & $\begin{array}{l}\text { Okul Öncesi Öğret. } \\
\text { Diğer }\end{array}$ & $\begin{array}{l}127 \\
33 \\
\end{array}$ & $\begin{array}{l}33,0000 \\
32,6364 \\
\end{array}$ & $\begin{array}{l}4,21637 \\
2,92423 \\
\end{array}$ & ,467 & 158 & 641 \\
\hline Cesaret & $\begin{array}{l}\text { Okul Öncesi Öğret. } \\
\text { Diğer }\end{array}$ & $\begin{array}{l}127 \\
33 \\
\end{array}$ & $\begin{array}{l}15,7165 \\
15,3636 \\
\end{array}$ & $\begin{array}{l}2,49729 \\
1,74675 \\
\end{array}$ & ,764 & 158 & ,446 \\
\hline Merak & $\begin{array}{l}\text { Okul Öncesi Öğret. } \\
\text { Diğer }\end{array}$ & $\begin{array}{l}127 \\
33 \\
\end{array}$ & $\begin{array}{l}12,7087 \\
12,5758\end{array}$ & $\begin{array}{l}1,71413 \\
1,43680\end{array}$ & ,409 & 158 & 683 \\
\hline Şüphe Etme & $\begin{array}{l}\text { Okul Öncesi Öğret. } \\
\text { Diğer }\end{array}$ & $\begin{array}{l}127 \\
33\end{array}$ & $\begin{array}{l}8,4409 \\
8,3636\end{array}$ & $\begin{array}{l}1,08857 \\
1,22010\end{array}$ & ,354 & 158 & ,724 \\
\hline Esneklik & $\begin{array}{l}\text { Okul Öncesi Öğret. } \\
\text { Diğer }\end{array}$ & $\begin{array}{l}127 \\
33\end{array}$ & $\begin{array}{l}12,6693 \\
12,6970\end{array}$ & $\begin{array}{l}1,57890 \\
1,18545\end{array}$ &,- 094 & 158 & ,925 \\
\hline
\end{tabular}


Tablo 3'e göre öğretmenlerin ölçekten aldıkları toplam puanlar mezun oldukları bölüme bağlı olarak anlamlı farklılık göstermemektedir $(\mathrm{t}=$ ,407, sd=158, p=,685). Aynı şekilde öğretmenlerin ölçeğin alt boyutlarından aldıkları puanlar da mezun oldukları bölüme bağlı olarak anlamlı farklılık göstermemektedir.

Tablo 4. Öğretmenlerin Yaşına Göre Marmara Yaratıcı Düşünme Ĕ̆ilimleri Ölçeğinden Aldıkları Puanlara İlişkin Anova Sonuçları

\begin{tabular}{|c|c|c|c|c|c|c|}
\hline & $\begin{array}{l}\text { Varyansın } \\
\text { Kaynağ1 }\end{array}$ & $\begin{array}{l}\text { Kareler } \\
\text { Toplamı }\end{array}$ & sd & $\begin{array}{l}\text { Kareler } \\
\text { Ortalaması }\end{array}$ & $\mathbf{F}$ & p \\
\hline $\begin{array}{l}\text { Toplam } \\
\text { puan }\end{array}$ & $\begin{array}{l}\text { Gruplar Arası } \\
\text { Gruplar İçi } \\
\text { Toplam }\end{array}$ & $\begin{array}{l}20,244 \\
19541,000 \\
19561,244 \\
\end{array}$ & 159 & $\begin{array}{l}10,122 \\
124,465\end{array}$ & ,081 & ,922 \\
\hline Öz disiplin & $\begin{array}{l}\text { Gruplar Arası } \\
\text { Gruplar İçi } \\
\text { Toplam }\end{array}$ & $\begin{array}{l}19,101 \\
1177,842 \\
1196,944 \\
\end{array}$ & 159 & $\begin{array}{l}9,551 \\
7,502\end{array}$ & 1,273 & 283 \\
\hline $\begin{array}{l}\text { Yenilik } \\
\text { Arama }\end{array}$ & $\begin{array}{l}\text { Gruplar Arası } \\
\text { Gruplar İçi } \\
\text { Toplam }\end{array}$ & $\begin{array}{l}2,852 \\
2514,248 \\
2517,100 \\
\end{array}$ & 159 & $\begin{array}{l}1,426 \\
16,014\end{array}$ & ,089 & ,915 \\
\hline Cesaret & $\begin{array}{l}\text { Gruplar Arası } \\
\text { Gruplar İçi } \\
\text { Toplam }\end{array}$ & $\begin{array}{l}614 \\
886,080 \\
886,694 \\
\end{array}$ & 159 & $\begin{array}{l}, 307 \\
5,644\end{array}$ & ,054 & ,947 \\
\hline Merak & $\begin{array}{l}\text { Gruplar Arası } \\
\text { Gruplar İçi } \\
\text { Toplam }\end{array}$ & $\begin{array}{l}1,407 \\
435,337 \\
436,744 \\
\end{array}$ & 159 & $\begin{array}{l}, 703 \\
2,773\end{array}$ & ,254 & ,776 \\
\hline Şüphe Etme & $\begin{array}{l}\text { Gruplar Arası } \\
\text { Gruplar İçi } \\
\text { Toplam }\end{array}$ & $\begin{array}{l}, 382 \\
196,718 \\
197,100\end{array}$ & 159 & $\begin{array}{l}, 191 \\
1,253\end{array}$ & 152 & ,859 \\
\hline Esneklik & $\begin{array}{l}\text { Gruplar Arası } \\
\text { Gruplar İçi } \\
\text { Toplam }\end{array}$ & $\begin{array}{l}668 \\
358,432 \\
359,100\end{array}$ & 159 & $\begin{array}{l}, 334 \\
2,283\end{array}$ & ,146 & 864 \\
\hline
\end{tabular}

Tablo 4'e göre öğretmenlerin ölçekten aldıkları toplam puanlar yaşlarına bağlı olarak anlamlı farklılık göstermemektedir $(\mathrm{F}=, 081, \mathrm{sd}=159, \mathrm{p}=$ ,922). Aynı şekilde öğretmenlerin ölçeğin alt boyutlarından aldıkları puanlar da yaşlarına bağlı olarak anlamlı farklılık göstermemektedir.

Tablo 5'e göre öğretmenlerin ölçekten aldıkları toplam puanlar mesleki kıdemlerine bağlı olarak anlamlı farklılık göstermemektedir ( $\mathrm{F}=$,757, 
$\mathrm{sd}=159, \mathrm{p}=, 520)$. Aynı şekilde öğretmenlerin ölçeğin alt boyutlarından aldıkları puanlar da mesleki kıdemlerine bağlı olarak anlamlı farklılık göstermemektedir.

Tablo 5. Öğretmenlerin Mesleki Kıdemlerine Göre Marmara Yaratıcı Düşünme Ĕ̆ilimleri Ölçeğinden Aldıkları Puanlara İlişkin Anova Sonuçları

\begin{tabular}{|c|c|c|c|c|c|c|}
\hline & $\begin{array}{l}\text { Varyansın } \\
\text { Kaynağ1 }\end{array}$ & $\begin{array}{l}\text { Kareler } \\
\text { Toplamı } \\
\end{array}$ & sd & $\begin{array}{l}\text { Kareler } \\
\text { Ortalaması } \\
\end{array}$ & $\mathbf{F}$ & p \\
\hline $\begin{array}{l}\text { Toplam } \\
\text { puan }\end{array}$ & $\begin{array}{l}\text { Gruplar Arası } \\
\text { Gruplar İçi } \\
\text { Toplam }\end{array}$ & $\begin{array}{l}280,849 \\
19280,395 \\
19561,244 \\
\end{array}$ & 159 & $\begin{array}{l}93,616 \\
123,592\end{array}$ & 757 & ,520 \\
\hline Öz disiplin & $\begin{array}{l}\text { Gruplar Arası } \\
\text { Gruplar İçi } \\
\text { Toplam }\end{array}$ & $\begin{array}{l}42,250 \\
1154,693 \\
1196,944 \\
\end{array}$ & 159 & $\begin{array}{l}14,083 \\
7,402\end{array}$ & 1,903 & 131 \\
\hline $\begin{array}{l}\text { Yenilik } \\
\text { Arama }\end{array}$ & $\begin{array}{l}\text { Gruplar Arası } \\
\text { Gruplar İçi } \\
\text { Toplam }\end{array}$ & $\begin{array}{l}12,451 \\
2504,649 \\
2517,100 \\
\end{array}$ & 159 & $\begin{array}{l}4,150 \\
16,055\end{array}$ & ,258 & 855 \\
\hline Cesaret & $\begin{array}{l}\text { Gruplar Arası } \\
\text { Gruplar İçi } \\
\text { Toplam }\end{array}$ & $\begin{array}{l}11,938 \\
874,755 \\
886,694 \\
\end{array}$ & 159 & $\begin{array}{l}3,979 \\
5,607\end{array}$ & 710 & ,548 \\
\hline Merak & $\begin{array}{l}\text { Gruplar Arası } \\
\text { Gruplar İçi } \\
\text { Toplam }\end{array}$ & $\begin{array}{l}1,139 \\
435,605 \\
436,744 \\
\end{array}$ & 159 & $\begin{array}{l}, 380 \\
2,792\end{array}$ & 136 & ,938 \\
\hline Şüphe Etme & $\begin{array}{l}\text { Gruplar Arası } \\
\text { Gruplar İçi } \\
\text { Toplam }\end{array}$ & $\begin{array}{l}1,565 \\
195,535 \\
197,100 \\
\end{array}$ & 159 & $\begin{array}{l}, 522 \\
1,253\end{array}$ & ,416 & ,742 \\
\hline Esneklik & $\begin{array}{l}\text { Gruplar Arası } \\
\text { Gruplar İçi } \\
\text { Toplam }\end{array}$ & $\begin{array}{l}6,692 \\
352,408 \\
359,100\end{array}$ & 159 & $\begin{array}{l}2,231 \\
2,259\end{array}$ & ,987 & ,400 \\
\hline
\end{tabular}

Tablo 6'ya göre öğretmenlerin ölçekten aldıkları toplam puanlar çalıştıkları yaş grubuna bağlı olarak anlamlı farklılık göstermemektedir ( $\mathrm{F}=$ ,257, sd=159, p=,773). Aynı şekilde öğretmenlerin ölçeğin alt boyutlarından aldıkları puanlar da çalıştıkları yaş grubuna bağlı olarak anlamlı farklılık göstermemektedir. 
Tablo 6. Öğretmenlerin Çalıştı̆̆ı Yaş Grubuna Göre Marmara Yaratıcı Düşünme Ĕ̆ilimleri Ölçeğinden Aldıkları Puanlara İlişkin Anova Sonuçları

\begin{tabular}{|c|c|c|c|c|c|c|}
\hline & $\begin{array}{l}\text { Varyansın } \\
\text { Kaynağ1 } \\
\end{array}$ & $\begin{array}{l}\text { Kareler } \\
\text { Toplamı } \\
\end{array}$ & sd & $\begin{array}{l}\text { Kareler } \\
\text { Ortalaması }\end{array}$ & $\mathbf{F}$ & $\mathrm{p}$ \\
\hline \multirow[t]{3}{*}{ Toplam puan } & Gruplar Arası & 63,952 & 159 & 31,976 & \multirow{3}{*}{ 257 } & \multirow{3}{*}{,773 } \\
\hline & Gruplar İçi & 19497,292 & & 124,187 & & \\
\hline & Toplam & 19561,244 & & & & \\
\hline \multirow[t]{3}{*}{ Öz disiplin } & Gruplar Arası & 4,394 & 159 & 2,197 & \multirow{3}{*}{ 289 } & \multirow{3}{*}{,749 } \\
\hline & Gruplar İçi & 1192,550 & & 7,596 & & \\
\hline & Toplam & 1196,944 & & & & \\
\hline \multirow[t]{3}{*}{ Yenilik Arama } & a Gruplar Arası & 4,146 & 159 & 2,073 & \multirow{3}{*}{ 130 } & \multirow{3}{*}{879} \\
\hline & Gruplar İçi & 2512,954 & & 16,006 & & \\
\hline & Toplam & 2517,100 & & & & \\
\hline \multirow[t]{3}{*}{ Cesaret } & Gruplar Arası & 12,588 & 159 & 6,294 & \multirow{3}{*}{1,130} & \multirow{3}{*}{,325 } \\
\hline & Gruplar İçi & 874,106 & & 5,568 & & \\
\hline & Toplam & 886,694 & & & & \\
\hline \multirow[t]{3}{*}{ Merak } & Gruplar Arası & 2,675 & 159 & 1,337 & \multirow{3}{*}{, 484} & \multirow{3}{*}{ 617 } \\
\hline & Gruplar İçi & 434,069 & & 2,765 & & \\
\hline & Toplam & 436,744 & & & & \\
\hline \multirow[t]{3}{*}{ Şüphe Etme } & Gruplar Arası & 1,173 & 159 & ,587 & \multirow{3}{*}{,470 } & \multirow{3}{*}{,626 } \\
\hline & Gruplar İçi & 195,927 & & 1,248 & & \\
\hline & Toplam & 197,100 & & & & \\
\hline \multirow[t]{3}{*}{ Esneklik } & Gruplar Arası & 3,801 & 159 & 1,900 & \multirow{3}{*}{840} & \multirow{3}{*}{,434 } \\
\hline & Gruplar İçi & 355,299 & & 2,263 & & \\
\hline & Toplam & 359,100 & & & & \\
\hline
\end{tabular}

Tablo 7'ye göre öğretmenlerin ölçekten aldıkları toplam puanlar sınıf mevcuduna bağlı olarak anlamlı farklılık göstermemektedir $(t=-1,533$, $\mathrm{sd}=158, \mathrm{p}=, 127)$. Ancak öğretmenlerin ölçeğin cesaret alt boyutundan aldıkları puanlar sınıf mevcuduna bağlı olarak anlamlı farklılık göstermektedir(t= -3,062, sd=158, p=,003). Sınıfında 21 ve üzeri çocuk olan öğretmenlerin cesaret alt boyutundan aldıkları puanlar sınıfında 10-20 çocuk olan öğretmenlerin puanlarına göre anlamlı şekilde yüksektir. 
Tablo 7. Sınıf Mevcuduna Göre Marmara Yaratıcı Düşünme Eğilimleri Ölçeğinden Aldıkları Puanlara İlişkin Bağımsız Örneklemler t testi Analizi Sonuçları

\begin{tabular}{|c|c|c|c|c|c|c|c|}
\hline & Sinif Mevcudu & $\mathbf{N}$ & $\bar{x}$ & SS & $\mathbf{t}$ & sd & $\mathrm{p}$ \\
\hline Toplam & $10-20$ & 72 & 100,8889 & 11,56069 & $-1,533$ & 158 & ,127 \\
\hline Puan & 21 ve üzeri & 88 & 103,5795 & 10,60549 & & & \\
\hline \multirow{2}{*}{$\begin{array}{l}\text { Öz } \\
\text { disiplin }\end{array}$} & \multirow{2}{*}{$\begin{array}{l}10-20 \\
21 \text { ve üzeri }\end{array}$} & 72 & 19,7222 & 2,88377 & \multirow{2}{*}{$-1,239$} & \multirow{2}{*}{158} & \multirow{2}{*}{,217 } \\
\hline & & 88 & 20,2614 & 2,61514 & & & \\
\hline \multirow{2}{*}{$\begin{array}{l}\text { Yenilik } \\
\text { Arama }\end{array}$} & $10-20$ & 72 & 32,6528 & 4,20985 & \multirow[t]{2}{*}{,- 782} & \multirow[t]{2}{*}{158} & \multirow[t]{2}{*}{,435 } \\
\hline & 21 ve üzeri & 88 & 33,1477 & 3,78909 & & & \\
\hline \multirow{2}{*}{ Cesaret } & $10-20$ & 72 & 15,0278 & 2,61616 & \multirow[t]{2}{*}{$-3,062$} & \multirow[t]{2}{*}{158} & \multirow[t]{2}{*}{, $003^{*}$} \\
\hline & 21 ve üzeri & 88 & 16,1477 & 2,00883 & & & \\
\hline \multirow[t]{2}{*}{ Merak } & $10-20$ & 72 & 12,5000 & 1,79984 & \multirow[t]{2}{*}{$-1,254$} & \multirow[t]{2}{*}{158} & \multirow[t]{2}{*}{ 212 } \\
\hline & 21 ve üzeri & 88 & 12,8295 & 1,52543 & & & \\
\hline \multirow{2}{*}{ Şüphe Etme } & $10-20$ & 72 & 8,3611 & 1,17851 & \multirow[t]{2}{*}{,- 655} & \multirow[t]{2}{*}{158} & \multirow[t]{2}{*}{, 513} \\
\hline & 21 ve üzeri & 88 & 8,4773 & 1,06109 & & & \\
\hline \multirow{2}{*}{ Esneklik } & $10-20$ & 72 & 12,6250 & 1,51460 & \multirow{2}{*}{,- 380} & \multirow{2}{*}{158} & \multirow{2}{*}{ 705 } \\
\hline & 21 ve üzeri & 88 & 12,7159 & 1,50057 & & & \\
\hline
\end{tabular}

Tablo 8. Hizmet içi Eğitime Katılma Durumuna Göre Marmara Yaratıcı Düşünme Ĕ̆ilimleri Ölçeğinden Aldıkları Puanlara İlişkin Bağımsız Örneklemler t testi Analizi Sonuçları

\begin{tabular}{|c|c|c|c|c|c|c|c|}
\hline & $\begin{array}{l}\text { Hizmet içi } \\
\text { eğitime katılma }\end{array}$ & $\mathbf{N}$ & $\bar{x}$ & SS & $\mathbf{t}$ & sd & $\mathbf{p}$ \\
\hline \multirow[t]{2}{*}{ Toplam Puan } & Katılıyor & 132 & 102,2576 & 10,71107 &,- 274 & 158 & 784 \\
\hline & Katılmiyor & 28 & 102,8929 & 12,94243 & & & \\
\hline \multirow[t]{2}{*}{ Öz disiplin } & Katıliyor & 132 & 19,9848 & 2,64138 &,- 338 & 158 & 736 \\
\hline & Katılmiyor & 28 & 20,1786 & 3,23240 & & & \\
\hline \multirow[t]{2}{*}{ Yenilik Arama } & Katıliyor & 132 & 32,8712 & 3,84510 &,- 370 & 158 & ,712 \\
\hline & Katılmiyor & 28 & 33,1786 & 4,62724 & & & \\
\hline \multirow[t]{2}{*}{ Cesaret } & Katıliyor & 132 & 15,6288 & 2,32611 &,- 173 & 158 & 862 \\
\hline & Katılmiyor & 28 & 15,7143 & 2,56554 & & & \\
\hline \multirow[t]{2}{*}{ Merak } & Katıliyor & 132 & 12,6212 & 1,58008 &,- 995 & 158 & ,321 \\
\hline & Katılmiyor & 28 & 12,9643 & 1,99039 & & & \\
\hline \multirow{2}{*}{ Şüphe Etme } & Katıliyor & 132 & 8,4621 & 1,08709 & ,915 & 158 & ,361 \\
\hline & Katılmiyor & 28 & 8,2500 & 1,23603 & & & \\
\hline \multirow{2}{*}{ Esneklik } & Katıliyor & 132 & 12,6894 & 1,46268 & & & \\
\hline & Katılmiyor & 28 & 12,6071 & 1,70705 & 262 & 158 & 793, \\
\hline
\end{tabular}


Tablo 8'e göre öğretmenlerin ölçekten aldıkları toplam puanlar hizmet içi eğitime katılma durumuna bağlı olarak anlamlı farklılık göstermemektedir $(t=-, 274, s d=158, p=, 784)$. Aynı şekilde öğretmenlerin ölçeğin alt boyutlarından aldıkları puanlar da hizmet içi eğitime katılma durumuna bağlı olarak anlamlı farklılık göstermemektedir.

\section{Tartışma ve Sonuç}

Okul öncesi öğretmenlerinin yaratıcı düşünme eğilimlerini çeşitli değişkenler açısından incelemek amacıyla gerçekleştirilen bu çalışmaya 160 okul öncesi öğretmeni katılmıştır.

Araştırma bulgularına göre çalışma grubundaki öğretmenlerin yaratıC1 düşünme eğilimlerinin yüksek olduğu bulunmuştur. Çoban (2016) tarafından yapılan çalışmada da okul öncesi öğretmenlerinin yaratıcılıklarının yüksek olduğu bulunmuştur. Yaratıcı olmak ve çocuklarda da yaratıcı düşünceyi geliştirici etkinlikler planlama becerisine sahip olmak, okul öncesi öğretmenlerinin sahip olması gereken becerilerdendir (Tuğrul,1993). Okul öncesi eğitim programlarında da okul öncesi öğretmenlerinin yaratıcı olmasının önemi vurgulanmaktadır. MEB 2013 okul öncesi eğitim programında programın amacına uygun bir şekilde uygulanabilmesi için öğretmenlerin yaratıcı olması gerektiği ifade edilmektedir. MEB 2006 okul öncesi eğitim programının temel özelliklerinden biri yaratıcılığın ön planda olmasıdır. Yaratıcılığın, programın başarıya ulaşmasında kritik kavram olduğu, öğretmenlerin öncelikle kendi yaratıcılıklarını geliştirmesi, daha sonra da çocukların yaratıcılıklarını geliştirmek için uygun yöntem ve teknikleri kullanmaları gerektiği ifade edilmiştir. Yaratıcı çocuklar için yaratıcı öğretmenlere ihtiyaç olduğu belirtilmiştir (MEB, 2006). Bu çalışmada elde edilen öğretmenlerin yaratıcı düşünme eğilimlerinin yüksek olduğu bulgusunun; okul öncesi eğitim program1nın etkili bir şekilde uygulanabilmesi açısından istenen bir sonuç olduğu söylenebilir.

Araştırma bulgularına göre öğretmenlerin yaratıcı düşünme eğilimlerinin mezun oldukları bölüme bağlı olarak anlamlı farklılık göstermediği bulunmuştur. Bu durumun çalışma grubundaki öğretmenlerin tamamının lisans mezunu olması ve mezun oldukları bölümlerin benzer olmasından kaynaklanabileceği düşünülmektedir. Yıldırım(2006) tarafından 
yapılan çalışmada da okul öncesi öğretmenlerinin yaratıcılıklarının mezun oldukları programa göre farklılaşmadığı bulunmuştur.

Demirel (2007), yaratıcı olmanın yaşla ilişkisi hakkında net sınırlar belirlemenin güç olduğunu ancak yaratıcı düşünmenin orta yetişkinlik döneminde en üst düzeye çıtı̆̆ını ifade etmektedir. Bu araştırmanın bulgularına göre öğretmenlerin yaratıcı düşünme eğilimlerinin yaşa ve mesleki kıdeme göre anlamlı farklılık göstermediği bulunmuştur. İlgili alan yazında bu bulguları destekleyen nitelikte bazı çalışmalara rastlanmıştır. Yıldırım (2006) tarafından yapılan çalışmada da anasınıfı öğretmenlerinin yaratıcılık düzeylerinin yaşa ve meslekteki hizmet sürelerine göre farklılaşmadığı saptanmıştır. Çoban(2016) tarafından yapılan çalışmada da öğretmenlerin yaşı ile yaratıcıkları arasında anlamlı fark olmadığı görülmüştür. Dursun ve Ünüvar (2011) tarafından yapılan çalışmada okul öncesi öğretmenlerin mesleki deneyimlerine göre, okulöncesi dönemde yaratıcılığı engelleyen faktörlere ilişkin görüşlerinin anlamlı düzeyde farklılaşmadığı sonucu elde edilmiştir.

Zembat, İlçi Küsmüş ve Yılmaz (2018) tarafından yapılan çalışmada ise bu çalışmanın bulgularından farklı şekilde okul öncesi öğretmenlerinin yaratıcı düşünme eğilimlerinin yaşa ve mesleki kıdem değişkenine göre anlamlı farklılık gösterdiği bulunmuştur. 36 ve üstü yaş aralığındaki öğretmenlerin ölçekten aldıkları puanlar 21-25 yaş aralığındaki öğretmenlerden daha yüksek bulunmuştur. 11-15 yıl ile 16 ve üstü yıl mesleki kıdeme sahip öğretmenlerin ölçekten aldıkları puanların da 0-5 yıl mesleki kıdeme sahip öğretmenlerden daha yüksek olduğu bulunmuştur.

Araştırma bulgularına göre öğretmenlerin yaratıcı düşünme eğilimlerinin çalıştıkları yaş grubuna bağlı olarak anlamlı farklılık göstermediği görülmüştür. Uzman (2003) tarafından yapılan çalışmada da okulöncesi eğitim kurumlarında çalışan öğretmenlerin, yaratıcı düşünmelerinin akıcılık, esneklik ve özgünlük düzeylerinde çalıştıkları sınıftaki çocukların yaşlarına göre anlamlı farklılık göstermediği bulgusuna ulaşılmıştır.

Araştırma bulgularına göre öğretmenlerin yaratıcı düşünme eğilimlerinin sınıf mevcuduna bağlı olarak anlamlı farklılık göstermediği bulunmuştur. Benzer şekilde Zembat, İlçi Küsmüş ve Yılmaz(2018)'ın çalışmasında da okul öncesi öğretmenlerinin yaratıcı düşünme eğilimlerinin sınıftaki çocuk sayısı değişkenine göre anlamlı bir farklılık göstermediği bulunmuştur. 
Araştırma bulgularına göre öğretmenlerin ölçeğin cesaret alt boyutundan aldıkları puanların sınıf mevcuduna bağlı olarak anlamlı farklılık gösterdiği bulunmuştur. Sınıfında 21 ve üzeri çocuk olan öğretmenlerin cesaret alt boyutundan aldıkları puanlar sınıfinda 10-20 çocuk olan öğretmenlerin puanlarına göre anlamlı şekilde yüksektir. MEB Okul Öncesi Eğitim ve İlköğretim Kurumları Yönetmeliğine (2014) göre bir sınıfta bulunması gereken çocuk sayısının 10'dan az 20'den fazla olmaması esastır. Ancak talep olması ve okulun imkânlarının yeterli olması hâlinde çocuk sayısının arttırılabileceği ifade edilmektedir. Bu nedenle 20'den fazla çocuğun ve tek öğretmenin bulunduğu sınıflar da bulunmaktadır. Ancak NAEYC standartlarına göre sınıflarda bulunması gereken çocuk sayısı ve yetişkin/çocuk oranı düşünüldügüünde ülkemizdeki sınıflarda çocuk sayısının ve yetişkin/çocuk oranının yüksek olduğu söylenebilir. $\mathrm{Bu}$ oranın yüksek olması ve sınıfların kalabalık olması, öğretmenlerin eğitim ortamında yaşadıkları sorunların başında gelmektedir (Başturan, 2018). Yaratıcılık probleme farklı çözüm yolları bulma (Torrance,1965) olarak tanımlanmaktadır. Bu tanımdan hareketle sınıfında daha fazla çocuk olan öğretmenlerin cesaret boyutunda daha yüksek puan almalarının; daha fazla sorun yaşamalarından, yaşadıkları sorunlara çözüm yolu bulmak için farklı yolları denemelerinden kaynaklandığı söylenebilir.

Araştırma bulgularına göre öğretmenlerin yaratıcı düşünme eğilimlerinin hizmet içi eğitime katılma durumuna bağlı olarak anlamlı farklılık göstermediği görülmüştür. Uzman (2003) tarafından yapılan çalışmada okulöncesi eğitim kurumlarında çalışan öğretmenlerin yaratıcılık ile ilgili hizmet içi eğitim kursuna katılıp katılmama durumlarına göre yaratıcılığın özgünlük boyutunda anlamlı farklılıklar gösterdiği ancak akıcılık ve esneklik boyutunda anlamlı bir fark görülmediği bulunmuştur.

Sonuç olarak, öğretmenlerin yaratıcı düşünme eğilimlerinin yüksek olduğu; yaratıcı düşünme eğilimleri ile yaş, mezun olunan bölüm, medeni durum, çocuk sahibi olma durumu, mesleki kıdem, sınıfında bulunan çocuk sayısı, sınıfındaki çocukların yaşı, hizmet içi eğitimlere katılma durumu arasında anlamlı fark olmadığı görülmüştür. 


\section{Öneriler}

$\mathrm{Bu}$ çalışmada okul öncesi öğretmenlerinin yaratıcı düşünme eğilimleri belirlenmeye çalışılmıştır. Okul öncesi öğretmen adaylarının yaratıcı düşünme eğilimlerini belirlemeye ve karşılaştırmalı olarak incelemeye yönelik çalışmalar yapılabilir.

Farklı branşlardaki öğretmenlerin yaratıcı düşünme eğilimlerinin incelendiği çalışmalar yapılabilir.

Cinsiyet, eğitim düzeyi, mizah tarzları gibi değişkenler ile yaratıcı düşünme eğilimleri arasında ilişkinin incelendiği çalışmalar yapılabilir.

Okul öncesi öğretmenlerinin çocukların yaratıcı düşünme becerilerini geliştirmeye yönelik gerçekleştirdikleri uygulamaların incelendiği çalışmalar yapılabilir. 


\title{
EXTENDED ABSTRACT
}

\section{Creative Thinking Dispositions of The Preschool Teachers}

\author{
Seda Eskidemir Meral - Fatma Tezel Şahin \\ Akdeniz University, Gazi University
}

Creativity is the skill of being able to produce a new, original and beneficial idea or a product, getting out of cliché, being able to have a different point of view for a problem by making more different relations than others between concepts (Ayden and İşguzar, 2006). Torrence (1965) defined creativity as being sensible towards problems and unconformity; describing problems, defining challenges, looking for solutions, finding different ways of solutions to problems and trying them. Creative thinking is making a relation between the objects and thoughts which did not have a relation before (Rawlinson, 1995). Creativity is an innate ability, and being more creative could be taught (Üstündağ, 2014). Studies showed that the educational programs that were prepared to improve creativity developed creativity (Dere and Ömeroğlu, 2018; Yıldız, 2000).

In order to support the creativity of children, it is of importance that teachers should develop their creativity as well (Argun, 2012). Children in the classes of creative teachers are creative. If one is not creative, it is difficult to teach and support creativity (Üstündağ, 2014). For that reason, it is believed that preschool teachers should have creative thinking skills and children should know how to develop this skill in order that children could develop their creative thinking skills. Torrence (1969) explained that the creativity of children reaches the highest level at the age of four and so preschool period should be regarded as the golden years of creativity (cited in Sönmez Ektem, 2017). The fact that preschool teacher is creative, he believes in the development of creativity of children and that they make arrangements in line with it will form a creative atmosphere (Çetingöz, 2002). It is likely to say that being a creative preschool teacher is of importance in terms of the fact that it is open to chil- 
dren's different features and skills, to the ways of their expressing themselves, to different ideas, that it allows children to be independent, and that they form an independent environment supporting the creativity where they can act freely. Creative teachers help children to dream, to find different ways of solution to the problem, to come up with different new ideas and to be aware of their own skills and powers by making an interaction with different materials (Argun, 2012). Creative teachers find the ways of coping with the mistakes they make but those who are not creative are even not aware of the mistakes they make (Üstündağ, 2014, cited in Bartel, 2000). Upon the revision of the related literature, it is likely to see that there are some studies claiming that the creativity of preschool teachers is high (Çoban, 2016) and that preschool teachers believe the importance of creativity (Alkuş and Olgan 2014; Cheung and Leung, 2013, Yildırım, 2006). Besides that, there some other studies pointing out that the activities for which preschool teachers apply are inadequate in terms of supporting creativity (Sönmez Ektam, 2017) and that preschool teachers need a support to develop creativity (Cheung and Leung, 2013).

It is thought that preschool teachers' having creative thinking skills will affect the creativity of children in classrooms and increase the quality of preschool education. In this sense, the purpose of the current study is to investigate the creative thinking dispositions of preschool teach in terms of different variables. Depending on this basic purpose, the following questions were tried to be answered:

At what level are the creative thinking dispositions of preschool teachers?

Is there a significant difference between the creative thinking dispositions of preschool teachers in terms of socio-demographic features (the school graduated, age, experience in occupation, the age group worked, the number of students in the class, the status of participation in inservice training courses)?

Survey model was used in the study. Survey method aims at describing a case in the past and in the present as it is (Karasar, 2005). In the current study, the creative thinking dispositions of preschool teacher were tried to be defined.

The working group of the study was made up of 160 preschool teaches working at a preschool education institution. The data of the study 
was collected through "General Information Form" that was prepared to determine the personal information of the teacher and "Marmara Scale of Creative Thinking Dispositions" that was developed by Özgenel and Çetin (2017). Marmara Scale of Creative Thinking Dispositions is a fivepoint Likert scale that was composed of 25 items. The scale that was made up of 6 dimensions as "Looking for innovation", "Courage", "Selfdiscipline", "Curiosity", "Suspecting" and "Flexibility" measures the creative thinking dispositions of individuals. Cronbach alpha internal consistency coefficient for the whole scale was calculated as .87. The lowest score to be obtained in the scale is 25 while the highest is 125 . The high score to be obtained in the scale shows that creative thinking disposition of the individual is high. The data of the study was collected from the volunteer teachers in a written form with the consents taken from the related institutions in the spring term of 2018-2019 academic year. In the analysis of the data, SPSS 23.0 package program was used. Statistics like percentages and frequencies were tabulated. The scores obtained from the scales for skewness and kurtosis values were calculated between -1.5 and +1.5 interval. As all the data was between these intervals, it was thought that it is a normal distribution. In order to determine the differences depending on the variable of the program graduated, the number of students in the class, the status of participation in an in-service training course, Unpaired T Test was used. In order to determine the differences depending on the age of the teachers, occupational experience, and the age group worked, Variance Analysis was used.

At the end of the research, it was found that creative thinking dispositions of the teachers were high; there was no significant difference between the creative thinking dispositions and the age, the department graduated, marital status, the status of having a child, occupational experience, the number of children in the classroom, the ages of the children in the class, and the status of participating in an in-service training course. According to the findings of the research, it was found that the score the teachers obtained from the sub-dimension of courage had a significant difference in terms of the number of the students in the class. The scores that the teachers who had 21 and more students obtained in the sub-dimension of courage were significantly high compared to the teachers who had 10-20 students. 
In the current study, the creative thinking dispositions of preschool teachers were tried to be determined. It is likely to conduct another study to determine the creative thinking dispositions of the candidate teachers and investigate them comparatively. It is also likely to carry out the creative thinking dispositions of teachers in different branches. It is possible to conduct studies to investigate the relation between such variables as gender, educational level, humour styles and creative thinking dispositions. Some other studies could be conducted to investigate the applications that preschool teachers practice to develop the creative thinking dispositions of children.

\section{Kaynakça / References}

Alkuş, S., ve Olgan, R. (2014). Pre-service and in-service preschool teachers' views regarding creativity in early childhood education. Early Child Development and Care, 184 (12), 1902-1919.

Argun, Y. (2012). Okul öncesi dönemde yaratıcıllk ve eğitimi. Ankara: Anı Yayincilik.

Ayden, C. ve İşgüzar, S. (2016). Üniversite öğrencilerinin yaratıcılık düzeyleri ve motivasyonları arasındaki ilişkiyi incelemeye yönelik araştırma. Furat Üniversitesi Sosyal Bilimler Dergisi, 26 (2), 201- 218.

Başturan, C. (2018). Devlet ve özel okul öncesi eğitim kurumlarında görev yapan ögretmenlerin mesleki sorun tanımlarının incelenmesi. Yayımlanmamış yüksek lisans tezi, Okan Üniversitesi, İstanbul.

Broinowski, I. (2002). Toward creativity in early childhood education: a case study of the creative processes used by early childhood educators in curriculum planning for young children. Unpublished Phd Thesis, University of South Australia, Australia.

Cheung, R.H.P. ve Leung, C.H. (2013). Preschool teachers' beliefs of creative pedagogy: Important for fostering creativity. Creativity Research Journal, 25 (4), 397-407.

Çetingöz, D. (2002). Okul öncesi eğitimi öğretmenliğgi öğrencilerinin yaratıcı düşünme becerilerinin gelişiminin incelenmesi. Yayımlanmamış yüksek lisans tezi, Dokuz Eylül Üniversitesi, İzmir.

Çoban, Ç. (2016). Okul öncesi öğretmenlerinin yaratıcılı düzeylerinin incelenmesi. Yayımlanmamış yüksek lisans tezi. Dumlupınar Üniversitesi, Uşak. 
Demirel, Ö. (2007). Kuramdan uygulamaya ĕgitimde program geliştirme. Ankara: Pegema Yayıncilık.

Dere, Z. ve Ömeroğlu, E . (2018). Yaratıcılık eğitim programının çocukların yaratıcı davranışlarına etkisinin incelenmesi. Cumhuriyet International Journal of Education, 7 (1), 1-15.

Dursun, M. A. ve Ünüvar, P. (2011). Okul öncesi eğitim döneminde yaratıc1lığg engelleyen durumlara ilişkin ebeveyn ve öğretmen görüşlerinin incelenmesi. Mehmet Akif Ersoy Üniversitesi Ĕ̆itim Fakültesi Dergisi, 11(21), 110-133.

Erdoğdu, Y. M. (2006). Yaratıcılık ile öğretmen davranışları ve akademik başarı arasındaki ilişkiler. Sosyal Bilimler Dergisi, 5(17), 95-106.

Karasar, N. (2005). Bilimsel araştırma yöntemi. (15. Baskı). Ankara: Nobel Yayın Dağıtım.

Milli Eğitim Bakanlığı Okul Öncesi Eğitimi Genel Müdürlüğü (2006). 36-72 aylık çocuklar için okul öncesi eğitim programı. Ankara: Milli Eğitim.

Milli Eğitim Bakanlığı Temel Eğitim Genel Müdürlüğü (2013). Okul öncesi eğitim programı (36-72 aylık çocuklar için.) Ankara: Milli Eğitim.

Milli Eğitim Bakanlığı. (2014) Okul öncesi eğitim ve ilköğretim kurumları yönetmeliği. http://www.mevzuat.gov.tr adresinden 21.05.2019 tarihinde alınmıştır.

Ölçer, S. ve Aşıkoğlu Özdemir, D . (2019). Okul öncesi öğretmenlerinin yaratıcılık düzeyleri ile 60-72 aylık çocukların fen öğreniminin karşılaştırilmasi. Journal of Awareness, 3(5), 837-856.

Özgenel, M. ve Çetin, M. (2017). Marmara yaratıcı düşünme eğilimleri ölçeğinin geliştirilmesi: Geçerlik ve güvenirlik çalışması. Marmara Üniversitesi Atatürk Ĕ̆itim Fakültesi Eğitim Bilimleri Dergisi, 46, 113-132.

Rawlinson, J.G.(1995), Yaratıcı düşünce ve beyin fırtınası (Çev: O.Değirmen). İstanbul: Rota Yayıncilık.

Sönmez-Ektem, I . (2017). Okul öncesi öğretmen adaylarının görüşlerine göre uygulama okullarındaki etkinliklerin yaratıcılık bağlamında değerlendirilmesi. Adıyaman Üniversitesi Sosyal Bilimler Enstitüsü Dergisi, 26, 523-547.

Torrance, E. P.(1965). Revarding creative behavior: Experiments in classroom creativity. NJ: PrenticeHall: Englewood Cliffs.

Tuğrul. B.A.(1993). Okul öncesi dönemde etkin öğretmen modeli. 9. Ya-Pa okul öncesi eğitimi ve yaygınlaştırılması semineri. İstanbul: Ya-Pa Yayınları. 
Uzman, E. (2003). Okul öncesi eğitim alanında çalışan öğretmenlerin yaratıcı düşünme becerilerinin gelişiminin incelenmesi. Yayımlanmamış yüksek lisans tezi, Dokuz Eylül Üniversitesi, İzmir.

Üstündağ, T. (2014). Yaratıcılı̆̆a yolculuk (6. Baskı). Ankara: PegemA Yayınc1lik.

Yıldırım, B. (2006). Öğretmenlerin yaratıcılı̆̆a bakış açısı ve anasınıfı çocuklarının yaratıcllk düzeylerinin, öğretmenin yaratıcılık düzeyine göre incelenmesi. Yayımlanmamış yüksek lisans tezi, Hacettepe Üniversitesi, Ankara.

Yıldız, F. Ü. (2000). Deneysel yaratıcılık programının 4-5 yaş çocuklarının sosyal ve bilişsel gelişimlerine etkileri. Yayınlanmamış yüksek lisans tezi, Selçuk Üniversitesi, Konya.

Zembat, R., İlçi Küsmüş,G. ve Yılmaz; H. (2018). Okul öncesi $\quad$ öğretmenlerinin yaratıcı düşünme eğilimleri ve sinıf yönetimleri. Değişen dünyada eğitim. Ankara: PegemA Yayıncilı.

Zeytun, S. (2010). Okulöncesi öğretmenliği öğrencilerinin yaratıcılı ve problem çözme düzeyleri arasındaki ilişkinin incelenmesi.Yayımlanmamış yüksek lisans tezi. Dokuz Eylül Üniversitesi, İzmir.

\section{Kaynakça Bilgisi / Citation Information}

Eskidemir-Meral, S. ve Tezel-Şahin, F. (2019). Okul öncesi öğretmenlerinin yaratıcı düşünme eğilimleri OPUS-Uluslararası Toplum Araştırmaları Dergisi, 13(19), 311-331. DOI: 10.26466/opus.580091 